\title{
Glycaemic index of cereal products explained by their content of rapidly and slowly available glucose
}

\author{
Klaus N. Englyst ${ }^{1}+\dagger$, Sophie Vinoy ${ }^{2} \dagger$, Hans N. Englyst ${ }^{1}$ and Vincent Lang ${ }^{2}$ \\ ${ }^{1}$ Englyst Carbohydrates - Research \& Services Ltd, 2 Venture Road, \\ Chilworth Science Park, Southampton, Hampshire SO16 7NP, UK \\ ${ }^{2}$ Danone Vitapole, Nutrivaleur, route départementale 128, 91767 Palaiseau cedex, France
}

(Received 27 March 2002 - Revised 9 October 2002 - Accepted 13 October 2002)

\begin{abstract}
Elucidating the role of carbohydrate quality in human nutrition requires a greater understanding of how the physico-chemical characteristics of foods relate to their physiological properties. It was hypothesised that rapidly available glucose (RAG) and slowly available glucose (SAG), in vitro measures describing the rate of glucose release from foods, are the main determinants of glycaemic index (GI) and insulinaemic index (II) for cereal products. Twenty-three products (five breakfast cereals, six bakery products and crackers, and twelve biscuits) had their GI and II values determined, and were characterised by their fat, protein, starch and sugar contents, with the carbohydrate fraction further divided into total fructose, RAG, SAG and resistant starch. Relationships between these characteristics and GI and II values were investigated by regression analysis. The cereal products had a range of GI (28-93) and II (61-115) values, which were positively correlated $\left(r^{2} 0 \cdot 22, P<0 \cdot 001\right)$. The biscuit group, which had the highest SAG content (8.6 (SD 3.7) g per portion) due to the presence of ungelatinised starch, was found to have the lowest GI value (51 (SD 14)). There was no significant association between GI and either starch or sugar, while RAG was positively $\left(r^{2} 0.54, P<0.001\right)$ and SAG was negatively $\left(r^{2} 0.63, P<0.001\right)$ correlated with GI. Fat was correlated with GI $\left(r^{2} 0.52, P<0.001\right)$, and combined SAG and fat accounted for $73.1 \%$ of the variance in GI, with SAG as the dominant variable. RAG and protein together contributed equally in accounting for $45.0 \%$ of the variance in II. In conclusion, the GI and II values of the cereal products investigated can be explained by the RAG and SAG contents. A high SAG content identifies low-GI foods that are rich in slowly released carbohydrates for which health benefits have been proposed.
\end{abstract}

Glycaemic index: Insulinaemic index: Dietary carbohydrate: Carbohydrate quality: Cereal products

Since its development in 1981, the glycaemic index (GI) has had a pivotal role in highlighting the variation in physiological responses associated with different carbohydratecontaining foods (Jenkins et al. 1981). This ranking of foods by the glycaemic responses elicited when equi-carbohydrate portions are consumed has provided a unique, and at times controversial, perspective on the issue of carbohydrate quality (Wolever, 1997; Bellisle, 2001). Low-GI diets have been successfully applied as a dietary therapy in diabetes mellitus and other conditions exhibiting derangements in carbohydrate and lipid metabolism (Brand-Miller, 1994). In these studies, the major dietary alterations were to the starch-containing foods, with the substitution of slowly digested low-GI products, such as pasta, wholegrain cereal and legumes, for rapidly digested high-GI products, such as bread, breakfast cereals and potatoes.

The relationship between the rate of starch digestion and GI has been established by investigations of in vitro amylolytic hydrolysis (O’Dea et al. 1981; Jenkins et al. 1982; Heaton et al. 1988; Bornet et al. 1989; Englyst et al. 1992; Granfeldt et al. 1992). The rate and extent of starch digestion is influenced by botanical origin as this determines the amylose:amylopectin ratio and the structural type of the starch granule (Gallant et al. 1992). The other important factor is food processing, which determines the extent of starch gelatinisation, particle size and the integrity of the

Abbreviations: BC, breakfast-cereal group; Bi, biscuit group; BP\&C, bakery-products and crackers group; GI, glycaemic index; II, insulinaemic index;

RAG, rapidly available glucose; RS, resistant starch; SAG, slowly available glucose.

* Corresponding author: Dr Klaus N. Englyst, fax +44 238076 9654, email Klaus@Englyst.co.uk

$\dagger$ K. N. E. and S. V. are joint first authors. 
plant cell wall (Heaton et al. 1988; Holm et al. 1988; Colonna et al. 1992; Holt \& Brand-Miller, 1994; Heijene et al. 1995). These physico-chemical variables of starchcontaining foods are difficult to characterise in a quantitative manner that relates to their likely physiological fate. Instead, the influence of such physico-chemical characteristics on the rate and extent of carbohydrate digestion can be measured, and this can then be used to provide a description of this nutritionally important aspect of the food.

In conjunction with studies on human subjects, we have developed analytical procedures that characterise dietary carbohydrates with regard to chemical composition and likely gastrointestinal fate (Englyst et al. 1992, 1999; Englyst \& Hudson, 1996). The glycaemic carbohydrate fraction that is available for absorption in the small intestine is measured as the sum of sugars and starch, excluding resistant starch (RS). We have divided the glycaemic glucose fraction (sum of glucose in the glycaemic carbohydrate fraction, but excluding lactose) into rapidly available glucose (RAG) and slowly available glucose (SAG), to reflect the likely rate of release and absorption of glucose.

In addition to the rate of carbohydrate digestion, foodmediated effects on both gastrointestinal events and post-absorptive metabolism can influence the GI. Gastric emptying is affected by food particle size (Thomsen et al. 1994) and fat content (Gannon et al. 1993), as well as by viscous fibre, which also limits enzymatic hydrolysis in the small intestine by restricting access to the food bolus (Jenkins et al. 1978). Post-absorptive factors that can influence GI include the identity of the sugar moieties, which are metabolised differently (Lee \& Wolever, 1998), and the insulinotropic effect of protein, which can increase the clearance rate of circulating glucose (van Loon et al. 2000). This emphasises the fact that GI values do not represent a direct measure of carbohydrate absorption from the small intestine. Rather, the GI values are determined by the combined effect of all the properties of a food that influence the rate of influx and removal of glucose from the circulation. A better understanding of the mechanisms involved should provide insight into the concept of GI, and help to establish whether different types of low-GI diets are equally beneficial to health.

As cereal grains are the largest contributor to carbohydrate intake, it follows that altering the carbohydrate quality of cereal products is likely to have the most tangible effect on this aspect of nutrition. Considerable choice and flexibility exists for the consumer in their selection of cereal products based on the grain type, degree of refinement and type of processing (Prochaska et al. 2000). Unfortunately, with a few notable exceptions, the food-processing techniques employed in the manufacture of cereal products tend to result in the disruption of the food matrix and the gelatinisation of starch granules, thereby making them readily digestible and consequently they generally have high GI values. The challenge is to identify techniques for cereal processing that result in starch that is slowly digested, thereby achieving low-GI products.

Previously, we have shown that for a limited number of predominantly starchy foods, the division between RAG and SAG has physiological significance with regard to glycaemic response (Englyst et al. 1999). In the present paper, we extend our investigations on the correlations between the chemical and carbohydrate digestibility characteristics of cereal products and their GI and insulinaemic index (II) values. These relationships need to be established in order to achieve a greater understanding of the role of carbohydrate quality in nutrition.

\section{Subjects and methods}

\section{Test meals}

Twenty-three cereal products, selected for investigation on the basis that they may be interchangeable within a breakfast meal or snack, were collected from different countries (Table 1). The products encompass a range of ingredients and processing techniques that contribute to defining their physico-chemical properties. The predominant cereal present in these products is wheat, with a few exceptions where maize (cornflakes), rice (Special K) or oats (Alpen) represent the sole or major cereal component. Apart from the Alpen muesli, which contained steamed rolled oat kernels (and some dried fruit and nuts), the products were produced from flour and did not contain dense matrices. The other products in the breakfast-cereal group (BC) comprised flakes of extruded cereals, which are low in fat, with a moderate content of sugar. The bakery-product and crackers group (BP\&C) included two baguette meals and two brioche-type products where fat and milk are present during the baking process. The crackers were included within group BP\&C, as these are also produced by baking in the presence of fat and moisture. The biscuit group (Bi) was on average moderately high in fat and sugar, and in contrast with the other groups, several of the biscuits were baked under low-moisture conditions, which restricts the extent to which starch granules are gelatinised.

\section{Glycaemic index determination}

The GI values of the selected cereal products were determined using the previously described standard protocol (Wolever, 1991; Food and Agriculture Organization/ World Health Organization, 1998). The results were obtained from a series of seven sets of GI determinations, each of which included between eleven and fourteen healthy subjects.

Briefly, subjects who had maintained an overnight fast were fed the test product in a portion size that was calculated to contain $50 \mathrm{~g}$ carbohydrate (as determined by an initial analysis of total starch and sugar content). Within the individual sets, each subject was given the products being tested once in a randomised order. In addition, on three separate occasions each subject also consumed a $50 \mathrm{~g}$ glucose solution as the reference meal (anhydrous glucose (dextrose); Sigma Chemical Company, St Louis, MO, USA). Blood samples were taken before and 15, 30, 45, 60, 90 and 120 min after each meal commenced. Plasma glucose concentrations were measured in duplicate using an enzymatic method (Roche Diagnostica, Basle, Switzerland) and insulin was measured by radioimmunoassay. Incremental areas under the blood glucose response curves were calculated using the trapezoid rule, with only the area above the 


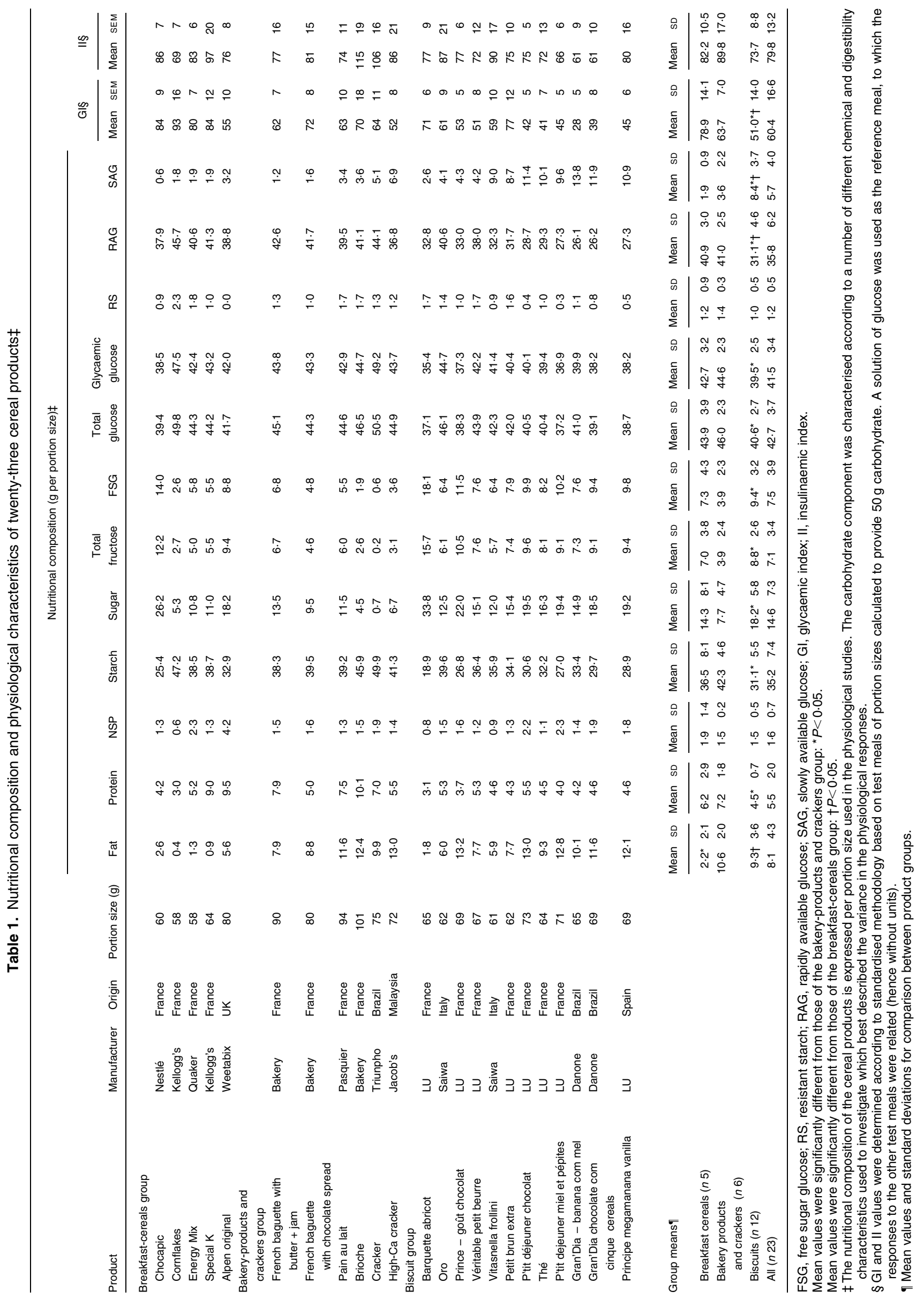


baseline being included. For each subject, a GI value for the test food was calculated as the incremental area under the blood glucose response curve for the test food, expressed as a percentage of the average incremental area under the blood glucose response curve for the three glucose reference test meals. The GI value of a product was calculated as the average of the GI values for that product obtained from the individual subjects. Calculation of II values for the test foods followed the principles utilised in the GI calculations.

\section{Dietary carbohydrate analysis}

Carbohydrate analysis of the products was performed using previously described procedures (Englyst et al. 1994, 2000). For the measurement of RAG, SAG and starch fractions, samples were minced using the specified procedure to simulate buccal mastication. Portions of the samples containing approximately $500 \mathrm{mg}$ carbohydrate were weighed into $50 \mathrm{ml}$ centrifuge tubes together with an internal standard. After an initial treatment with pepsin, the samples were incubated with a mixture of hydrolytic enzymes under controlled conditions of $\mathrm{pH}$, temperature, viscosity and mechanical mixing. Subsamples were taken from the incubation mixture exactly 20 and $120 \mathrm{~min}$ after the commencement of the hydrolysis. RAG and SAG values were calculated as the glucose released at $20 \mathrm{~min}$ and between 20 and $120 \mathrm{~min}$ respectively. Any starch remaining in the main incubation tube was dispersed and hydrolysed, with the increase in released glucose calculated as the RS fraction. Free sugar glucose and fructose (including that derived from sucrose) were determined after extraction procedures and incubation with invertase.

Five models describing different chemical and digestibility properties of the carbohydrate components were constructed from the analytical fractions. These were developed in a progressive fashion, with each successive carbohydrate model based on the previous one: model 1 , starch and sugar; model 2, starch, with the sugar fraction divided into total fructose and free sugar glucose components; model 3, fructose and the total glucose fraction calculated as the sum of free sugar glucose and glucose from starch; model 4, fructose, with the total glucose fraction divided into glycaemic glucose and RS; model 5, fructose and RS, with the glycaemic glucose divided into RAG and SAG.

To investigate the relationships between the physicochemical characteristics of foods and their in vitro digestibility profiles, three products from each group had their extent of starch gelatinisation determined by scanning differential calorimetry (Biliaderis et al. 1980). The results were expressed as the starch gelatinisation index (extent to which starch is gelatinised, with 100 representing total gelatinisation).

\section{Statistical analysis}

Student's $t$ test was used for comparisons between cereal product groups; a $P$ value $<0.05$ was considered significant. The relationships between nutrients and with the GI and II were investigated by univariate correlations. The total variance in GI and II that each of the carbohydrate models 1-5 could explain was investigated by ANOVA. The variance explained by fat, protein and NSP was also investigated. From these findings, simplified models were developed that best described the variance in GI and II values of the cereal products by their chemical and digestibility characteristics. Statistical analysis was performed with SPSS (version 9; SPSS Inc., Chicago, IL, USA).

\section{Results \\ Characteristics of the cereal products}

Table 1 shows the nutrient compositions of the twentythree foods that were investigated in the physiological studies, expressed per portion size, and with the corresponding GI and II values. There were significant differences between the three groups of products in their chemical and digestibility characteristics. There was less fat in BC than the other groups, and less protein and starch and more sugar in Bi than in BP\&C. The differences between groups extended to the detailed carbohydrate fractions, where Bi contained less RAG and more SAG than $\mathrm{BC}$, and $\mathrm{Bi}$ contained more total fructose than $\mathrm{BP} \& \mathrm{C}$. $\mathrm{Bi}$ had significantly lower GI values than BP\&C and BC. There was no significant difference in II values between groups. There was a positive correlation between GI and II values (Fig. 1), although II values were significantly higher $(P<0.001)$ than GI values.

The starch gelatinisation indices for the subset of products in the BC group were: Energy Mix 99, Chocapic 100, Special K 100. For the BP\&C group, the values were: French baguette with butter + jam 98 , French baguette with chocolate 98 , pain au lait 100. For the Bi group

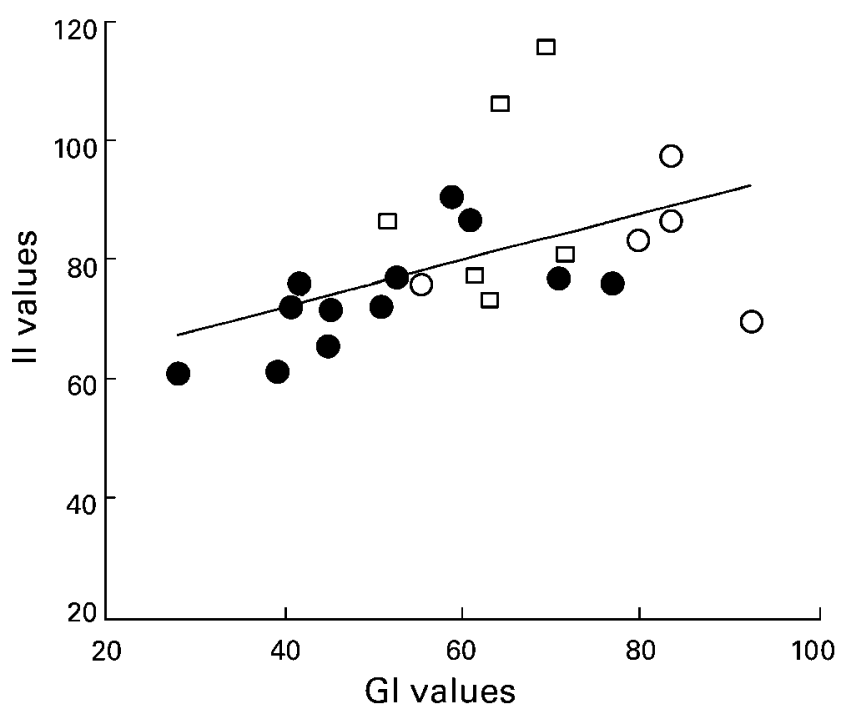

Fig. 1. Relationships between the glycaemic index (GI) and insulinaemic index (II) values of twenty-three cereal products, determined from test meals calculated to contain $50 \mathrm{~g}$ carbohydrate with a glucose solution as the reference meal. (O), Breakfast cereals; ( $\square$ ), bakery products and crackers; (๑), biscuits. For details of subjects, cereal products and procedures, see Table 1 and p. 330. $\mathrm{II}=57.5 \times 0.368 \times \mathrm{GI}, r^{2}=0.215, P<0.05$. 
the values were: P'tit déjeuner miel et pépites 56, Principe megamanana vanilla 50 , Véritable petit beurre 40. Fig. 2 shows that the Bi group had the lowest mean GI value, with the highest mean SAG content and the lowest mean starch gelatinisation index compared with the $\mathrm{BC}$ and $\mathrm{BP} \& \mathrm{C}$ groups.

\section{Relationships between nutrients}

In order to understand the statistical models that explain the variance in GI and II values, it is essential to establish the relationships that exist between the different carbohydrate fractions and the other nutritional components. Due to the
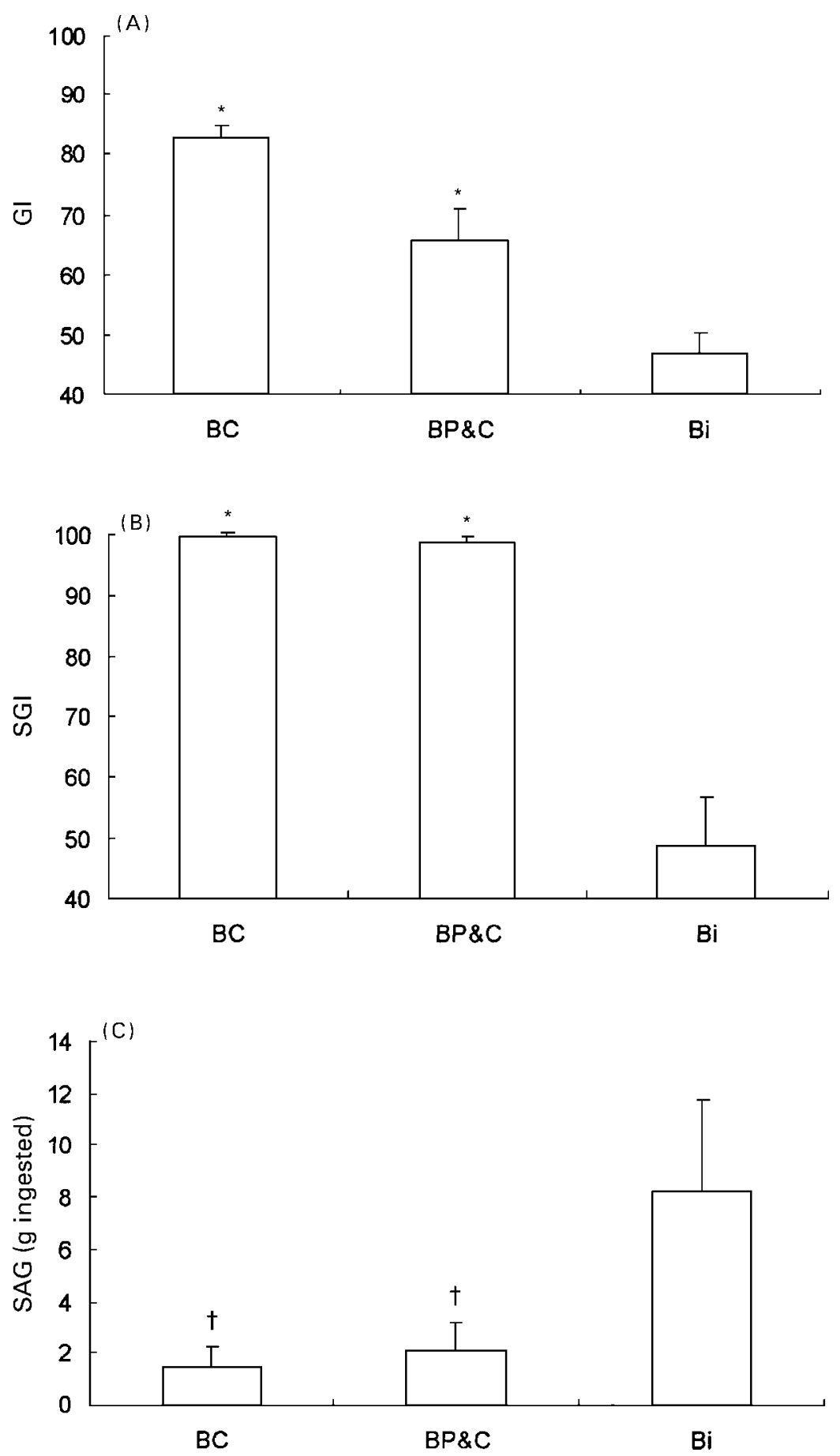

Fig. 2. (A) glycaemic index (GI), (B) starch gelatinisation index (SGI) and (C) slowly available glucose (SAG) content of subsets of three products from each of three cereal groups. BC, breakfast-cereals group; BP\&C, bakery-products and crackers group; $\mathrm{Bi}$, biscuit group. Values are means with standard deviations shown by vertical bars. For details of subjects, cereal products and procedures, see Table 1 and p. 330 . Mean values were significantly different from those of the Bi group: ${ }^{*} P<0.05, \dagger P=0.08$. 
design of the present study, with the carbohydrate content of the test meals fixed at $50 \mathrm{~g}$ carbohydrate, there is necessarily an interaction between those carbohydrate fractions described in the five models where a reciprocal relation with total carbohydrate exists, e.g. starch:sugar (model 1), total glucose:fructose (model 3). In addition, because the models build progressively on one another, a number of other correlations between carbohydrate fractions could be explained by their close links with other associated analytical fractions in different models, e.g. sugars:free sugar glucose:fructose (models 1 and 2), starch:total glucose:glycaemic glucose:RAG (models 1-5).

A summary of the significant univariate correlations between nutrients is shown in Table 2, which focuses on the RAG fraction in order to demonstrate its relative associations with other carbohydrate components. The positive correlation between starch and RAG in these products can be explained by the high proportion of the starch that is included in the RAG fraction (mean value 79.1 (range $55 \cdot 3-94.3) \%$ ) compared with the SAG (mean value 17.5 (range $2.2-41.2$ ) $\%$ ) or RS (mean value 3.4 (range 0.0$8.9) \%$ ) fractions. The total glucose and glycaemic glucose fractions, which combine the glucose components from starch and sugar, have strong positive correlations with RAG, reflecting the fact that an average of $83.5 \%$ total glucose in the products is included in the RAG fraction.

In model 5, RAG was correlated with total fructose, SAG and RS, with the SAG fraction demonstrating the strongest relationship. No significant relationships were observed between SAG and either starch or sugar, indicating that the SAG content of the products must be determined by the food-processing technique. Whilst the positive correlation between RS and starch is to be expected, there was a negative correlation between RS and NSP. There was no significant correlation between NSP and starch contents, and this finding remained even after the exclusion of Alpen, with its exceptionally high NSP value (in part due to its fruit and nut components), from the analysis.

The correlation of fat with RAG and SAG in these products is of particular interest. To some extent, this

Table 2. Selected relationships between the nutritional components of the cereal products investigated $\dagger$ (Univariate correlation coefficients)

\begin{tabular}{|c|c|c|c|c|c|}
\hline & Protein & Starch & RS & RAG & SAG \\
\hline NSP & $0.443^{\star}$ & & $-0.620^{\star *}$ & & \\
\hline Fat & & & & $-0.465^{\star}$ & $0.578^{\star *}$ \\
\hline Protein & & $0.462^{*}$ & & $0.458^{\star}$ & \\
\hline Starch & & & $0.469^{*}$ & $0.705^{\star \star}$ & \\
\hline Sugar & & & & $-0.567^{\star *}$ & \\
\hline Fructose & & & & $-0.573^{\star *}$ & \\
\hline FSG & & & & $-0.558^{\star \star}$ & \\
\hline $\begin{array}{l}\text { Total } \\
\text { glucose }\end{array}$ & & & $0.567^{\star \star}$ & $0 \cdot 816^{\star *}$ & $-0.427^{\star}$ \\
\hline $\begin{array}{c}\text { Glycaemic } \\
\text { glucose }\end{array}$ & & & & $0.803^{\star *}$ & $-0.443^{*}$ \\
\hline $\begin{array}{l}\text { RS } \\
\text { RAG }\end{array}$ & & & & $0.513^{*}$ & $\begin{array}{l}-0.419^{\star} \\
-0.866^{\star \star}\end{array}$ \\
\hline
\end{tabular}

RS, resistant starch; RAG, rapidly available glucose; SAG, slowly available glucose; FSG, free sugar glucose.

${ }^{\star} P<0.05,{ }^{* \star} P<0.01$.

†For details of products and procedures, see Table 1 and p. 330 . relationship reflects the different characteristics of the product groups, with $\mathrm{BC}$ having significantly lower fat and SAG contents than $\mathrm{Bi}$, and with $\mathrm{BP} \& \mathrm{C}$ intermediate in SAG but relatively high in fat content. Even so, positive correlations between fat and SAG were apparent within each group, but did not reach significance due to the small sample sizes. RAG was also positively correlated with protein content.

\section{Relationships with the glycaemic and insulinaemic indices}

In order to explain the variance in GI and II values, their correlation with the chemical and digestibility characteristics of the cereal products was investigated. The relationships between the carbohydrate fractions and the GI values are shown in Fig. 3, together with the total variance explained by each of the models 1-5. Neither starch nor sugar in model 1 were significantly correlated with GI, as was the case for free sugar glucose (model 2) and fructose (models 2-5). The positive correlations of GI with total glucose (model 3) and RS (models 4 and 5) can be explained by the analytical association that exists between these carbohydrate fractions and the RAG fraction (Table 2). GI was strongly correlated with both RAG and SAG contents in model 5.

The variance in GI that could be explained by the different carbohydrate models ranged from $33.8 \%$ for model 1 to $68.8 \%$ for model 5 (Fig. 3). The combined effect of fat, protein and NSP was to describe $59.1 \%$ of the variance in GI, but of these, only the fat content was significant $\left(r^{2} 0.52\right.$, $P<0 \cdot 01)$. The simplified model that best described the variance in GI combined the strongest variables, SAG and fat, and accounted for $73.1 \%$ (Fig. 4). The partial correlations of SAG and fat with GI within this model suggest that SAG is the dominant factor in comparison with fat.

The relationship between the carbohydrate fractions and the II values is summarised in Fig. 3, together with the variance in II explained by each of the models 1-5. Total fructose exhibited the strongest negative correlation and, through association, explained the correlations observed with sugars and free sugar glucose. Positive correlations were observed for total starch, total glucose and glycaemic glucose, all of which can be related to their association with RAG, which had the strongest positive correlation. A negative correlation between II and SAG was observed.

The variance in II that could be explained by the different carbohydrate models ranged from $27.6 \%$ for model 3 to $41.1 \%$ for model 5 (Fig. 3). Fat, protein and NSP together accounted for $46.4 \%$ of the variance, the majority of which was explained by the positive correlation with protein $\left(r^{2} 0.33, P<0 \cdot 01\right)$. The simplified model that best described the variance in II combined RAG and protein, and accounted for $45.0 \%$, (Fig. 4), with RAG and protein having similar partial correlations within this model.

\section{Discussion}

The present study has investigated the relationship between the chemical and digestibility characteristics of a selection of cereal products and their physiological properties (GI and II). Various models were investigated, which 


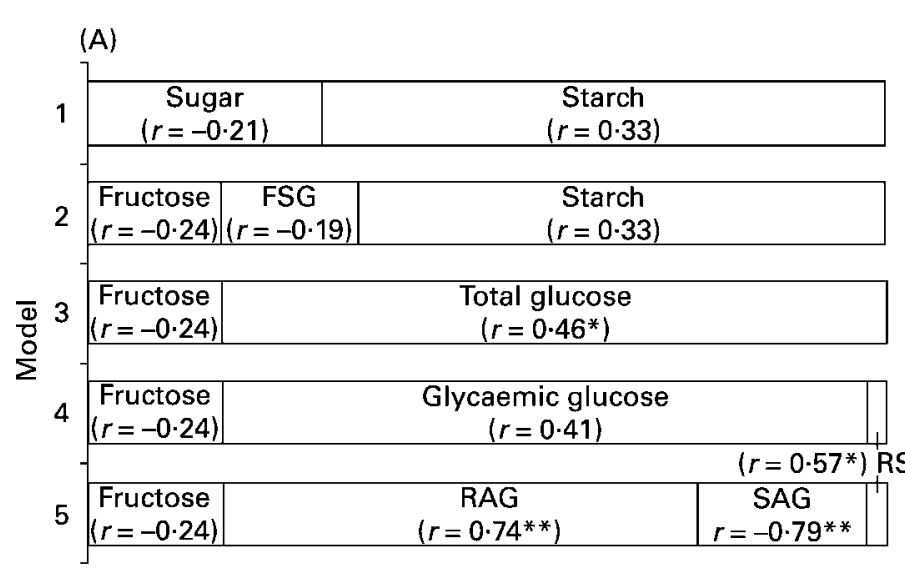

\section{Variance \\ explained \\ $33.8 \%$ \\ $45 \cdot 9 \%$ \\ $34 \cdot 2 \%$ \\ $40.0 \%$ \\ $68.8 \%$}

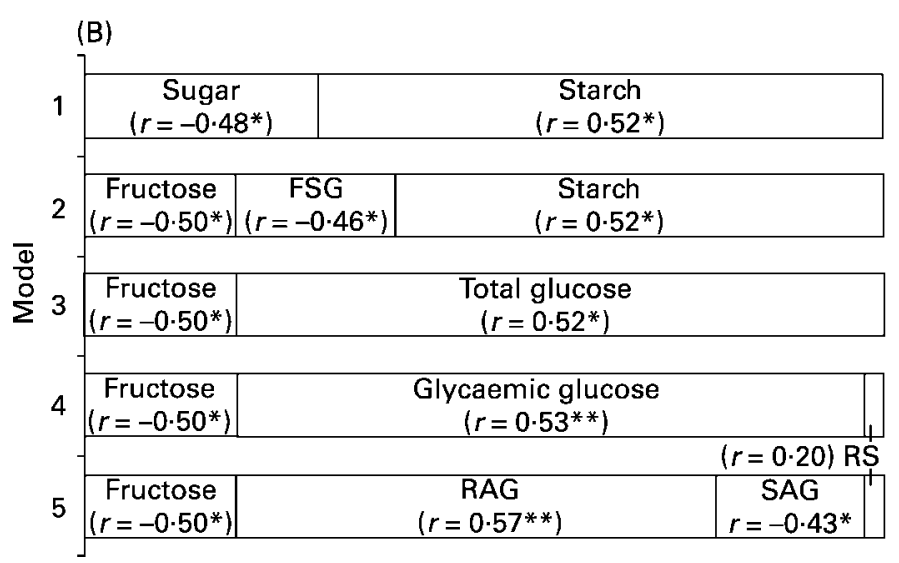

Variance

explained

$28.6 \%$

$35.5 \%$

$27.6 \%$

$28.5 \%$

$41.1 \%$

Fig. 3. Relationships between (A) glycaemic index and (B) insulinaemic index of twenty-three cereal products and their carbohydrate composition expressed as five models describing different chemical and digestibility characteristics. FSG, free sugar glucose; RS, resistant starch; RAG, rapidly available glucose; SAG, slowly available glucose. For details of subjects, cereal products and procedures, see Table 1 and p. 330. The univariate correlation coefficients $(r)$ for the individual carbohydrate fractions are provided alongside their labels ${ }^{\star} P<0.05$, ${ }^{\star \star} P<0.01$. The variance explained by each full model is derived from multiple covariate regression analysis $\left(r^{2}\right.$ values).

characterised the carbohydrate fraction progressively from solely chemical attributes in model 1 (starch and sugars) to a profile of the rate and extent of release in model 5 (fructose, RAG, SAG, and RS). The division of the glycaemic glucose fraction into RAG and SAG fractions (model 5) was found to describe $68.8 \%$ of the variance in GI, compared with $33.8 \%$ explained by the division into starch and sugars.

The twenty-three products investigated encompass a range of ingredients and processing techniques that contribute to defining their physico-chemical properties. Although starch is the main constituent of the products investigated in the present study, they also had a range of sugar, fat, protein and NSP contents. Each of these components has been found to influence glycaemic response, with much of this evidence based on observing the effects of addition of the component of interest to carbohydrate meals (Jenkins et al. 1978; Gannon et al. 1993; van Loon et al. 2000). The few studies that have specifically investigated the relationship between nutrient composition and GI value can be difficult to interpret as they incorporate a varied range of food groups.
For example, Trout et al. (1993) identified a negative relationship between protein content and GI, but this disappeared when the legume group, with its high-protein content and low GI value, was considered separately from the rest of the products. The present study was limited to the investigation of processed cereal products, thereby eliminating any interference associated with a wider range of food groups. This focus on cereal products did not restrict the range of GI and II values, but rather illustrated that the type of cereal product consumed can have a marked influence on physiological responses.

For the products investigated, the determinants of the digestibility profile of the carbohydrate fraction are the starch:sugar ratio used, the cereal type and the degree of food processing. The production of the breakfast cereals and bakery products investigated involves heating in the presence of moisture, which results in the gelatinisation of starch and its consequent rapid digestion. In contrast, several of the biscuits investigated were produced by baking under very-low-moisture conditions, which reduces the extent of starch gelatinisation and results in partially intact starch granules that are less susceptible to 

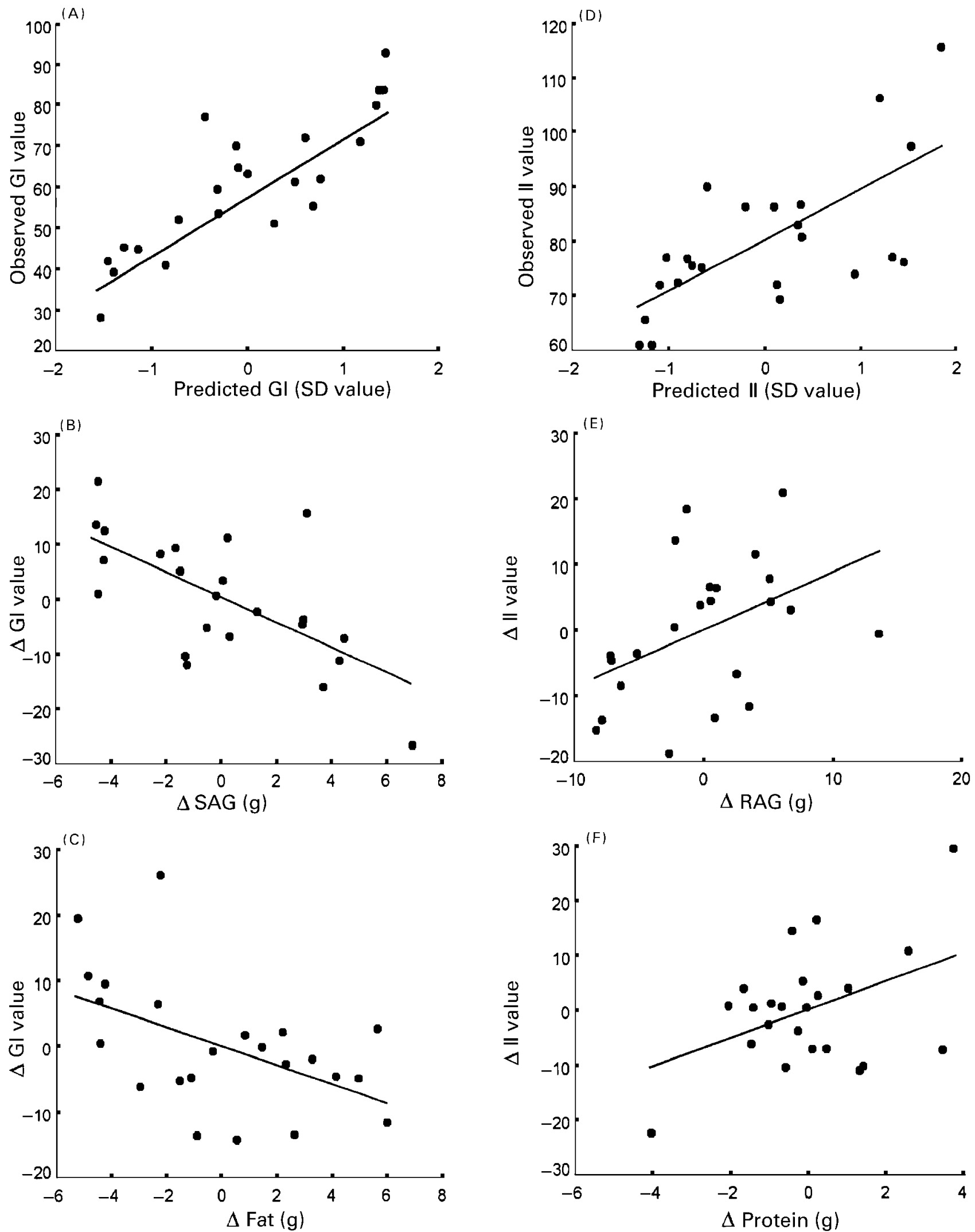

Fig. 4. Simplified models of the variance in glycaemic index (GI; (A), (B), (C)) and insulinaemic index (II; (D), (E), (F)) of twenty-three cereal products, explained by their chemical and carbohydrate digestibility characteristics. SAG, slowly available glucose; RAG, rapidly available glucose. (A), GI model with SAG + fat; GI = 85.8 - 2.335 $\times$ SAG + 1.493 $\times$ fat, $r^{2}=0.731$; (B), SAG (within Gl model), $r^{2}=0.445$; (C), fat (within GI model), $r^{2}=0.272$; (D), II model with RAG + protein; II = 35.8 + 0.821 $\times$ RAG $-2.624 \times$ protein, $r^{2}=0.450$; (E), RAG (within II model), $r^{2}=0.178 ;(\mathrm{F})$, protein (within II model), $r^{2}=0 \cdot 184$. For details of subjects, cereal products and procedures, see Table 1 and $\mathrm{p}$. 330 . 
the action of amylolytic enzymes (Bornet et al. 1989). This relationship between a low extent of starch gelatinisation and high SAG values was confirmed in the present study by the low starch gelatinisation index for the $\mathrm{Bi}$ group compared with the BP\&C group (Fig. 2).

Several of the relationships between nutrients identified in the present study are of interest, both in characterising the overall physico-chemical profile of the products, and in explaining observed correlations with GI and II values. For instance, the positive correlation between RS and GI is difficult to explain on its own, as the RS fraction is not absorbed in the small intestine and therefore cannot elicit a glycaemic response. Indeed, a negative relationship between RS content and GI has been reported, though the high RS products in that study contained 30-50\% starch as RS (Björck et al. 2000), compared with an average RS content of 3.5 (range 0.0-9.0) \% starch in the present study. Our present finding of a positive correlation between RS and GI is explained by the positive relationship that exists between RS and RAG in these products. This is typical of products where starch has been gelatinised, with the majority being readily digestible, except for the small amount of retrograded starch that resists digestion.

In the present study, the inter-relationship between RAG and SAG makes it difficult to identify which of these factors explains the strong correlations that they have with GI. However, we have previously shown that it is RAG, by virtue of its rapid digestion and absorption in the small intestine, that is responsible for the postprandial rise in blood glucose concentrations (Englyst et al. 1999). It follows that SAG exerts its reductive effect on GI values by replacing RAG in the test meal. An increase in the proportion of total fructose in a test meal will also result in a reduction in RAG and explains why foods high in fructose or sucrose have been reported to have only moderate GI values (Brand-Miller et al. 1995). In the present study, a correlation between fructose and GI was not observed, despite the fact that it replaced part of the RAG fraction. Consequently, this is likely to explain why the RAG fraction described only $55 \%$ of the variance in GI compared with the $63 \%$ explained by the SAG fraction. Despite its low GI value, high intakes of fructose are generally not recommended due to concerns about adverse effects on lipid profiles (Daly et al. 1997). It seems probable, therefore, that the greatest health benefits of low-GI diets will accompany those that contain carbohydrates that are slowly digested and absorbed.

The $51.5 \%$ variance in GI described by fat content is not fully explained by the association between fat and SAG, which together described $73 \%$ of the variance in GI (Fig. 4). Numerous studies have demonstrated that fat can lower the glycaemic response to foods (Welch et al. 1987; Collier et al. 1988; Gannon et al. 1993). However, a recent study found that while the addition of $40 \mathrm{~g}$ fat to a $75 \mathrm{~g}$ carbohydrate meal of pasta delayed the appearance of exogenous glucose in blood, this effect was not apparent with the addition of $15 \mathrm{~g}$ fat to the meal (Normand et al. 2001). The relatively small range of intake (mean value $8 \cdot 1$ (range $0 \cdot 4-13 \cdot 2$ ) g) in the present study would indicate that an effect of fat on gastric emptying is unlikely. Another possibility is that starch-lipid complexes may have formed during the processing of some of the cereal products, and this could restrict enzymatic hydrolysis (Biliaderis, 1991; Crowe et al. 2000). However, amylose-lipid complexes are developed with non-esterified fatty acids or monoacylglycerol, which are present in very small quantities in the cereal products investigated. It is also possible that the fat component of the meals triggered an incretin response with an insulinotropic effect (Welch et al. 1987; Collier et al. 1988), but if this was the case, the effect was either inconsistent or masked by other factors, as no significant correlation between fat and II was observed. The finding that the two high-fat baguette meals had moderately high GI values lends further support to the suggestion that fat per se only has a minor effect on GI in the present study.

Several studies have included measures of II values, which are of interest due to the role of insulin in glucose homeostasis and its regulatory effects in lipid metabolism. In addition, the large insulin demand associated with highGI diets has been proposed to be involved in the aetiology of diabetes (Salmeron et al. 1997; Wolever, 2000). The present study confirms the relationship between GI and II values for starchy foods, although the correlation is not as strong as reported previously (Björck et al. 2000). It is possible that this rather weak association, and the observation that II values were higher than GI values, could be explained by the combined insulinotropic effects of protein, fat and possibly of other undetermined properties of the foods. This is supported by the investigation into the glycaemic and insulinaemic responses to $1000 \mathrm{~kJ}$ portions of a range of foods (Holt et al. 1997). Holt et al. (1997) could only explain $23 \%$ of the variance in the insulin score by the glycaemic score of the foods, and only a further $10 \%$ could be accounted for by the macronutrient composition. Of the carbohydrate fractions investigated in the present study, RAG demonstrated the strongest correlation with II, but still only explained $32 \%$ of the variance. The observed positive correlation between protein and II is in agreement with previous findings (Kabadi, 1991; Trout et al. 1993; Brand-Miller et al. 1995), although the association between RAG and protein may in part explain this relationship. The model incorporating RAG and protein accounted for $45 \%$ variance in II, considerably less than could be identified for GI.

The present study has demonstrated that RAG and SAG, describing the rate of carbohydrate release from foods, are the carbohydrate fractions that best describe the variability in physiological attributes of the cereal products investigated. Although there appeared to be independent effects of fat on GI and of protein on II, these relationships may in part be explained by their correlations with RAG and SAG. The effect of protein and fat should not be completely dismissed, and indeed their presence in the foods investigated is probably responsible for some of the variance observed in GI and especially II values. This acts to highlight further the consistency of the effect of RAG and SAG on the physiological responses, in spite of the complexity of factors that can have an influence. It is apparent from the present study that food processing is the major determinant of the state of gelatinisation of starch and the SAG content of cereal products. The Bi 
group had the highest mean SAG content, although this group also exhibited the greatest range in the proportion of SAG in the starch fraction, reflecting the diversity in processing methods used in biscuit production. This demonstrates that limiting the extent of starch gelatinisation, as occurs with some types of biscuit manufacture, represents a feasible method by which to lower the GI values of cereal products.

In conclusion, the present paper has shown that carbohydrate identity and food processing largely determine the variation in GI values of cereal products, and that this is adequately reflected by the classification scheme describing the rate of carbohydrate release from foods. Specifically, the SAG measurement allows the identification of those low-GI foods containing carbohydrates that are slowly digested and absorbed, for which health benefits are likely to be associated. We suggest that the proposed classification scheme would be valuable in the further elucidation of the mechanisms by which carbohydrate quality can influence health.

\section{Acknowledgements}

We thank Marinos Elia and Steve Wootton from the Institute of Human Nutrition, University of Southampton, for their support and advice. This work was supported by Danone Vitapole.

\section{References}

Bellisle F (2001) Glycaemic Index and Health: the Quality of the Evidence. Montrouge, France: John Libbey Eurotext.

Biliaderis CG, Maurice TJ \& Vose JR (1980) Starch gelatinisation phenomena studied by scanning differential calorimetry. Journal of Food Science 45, 1669-1675.

Biliaderis CG (1991) The structure and interactions of starch with food constituents. Canadian Journal of Physiology and Pharmacology 69, 60-78.

Björck I, Liljeberg H \& Ostman E (2000) Low glycaemic-index foods. British Journal of Nutrition 83, Suppl., S149-S155.

Bornet FRJ, Fontvielle AM, Rizkalla S, Colonna P, Blayo A, Mercier C \& Slama G (1989) Insulin and glycaemic responses in healthy humans to native starches processed in different ways: correlation with in vitro $\alpha$-amylase hydrolysis. American Journal of Clinical Nutrition 50, 315-323.

Brand-Miller JC (1994) Importance of glycaemic index in diabetes. American Journal of Clinical Nutrition 59, Suppl., 747S-752S.

Brand-Miller J, Pang E \& Broomhead L (1995) The glycaemic index of foods containing sugars: comparison of foods with naturally occurring $v$. refined sugars. British Journal of Nutrition 73, 613-623.

Collier GR, Greenberg GR, Wolever TMS \& Jenkins DJA (1988) The acute effect of fat on insulin secretion. Journal of Clinical Endocrinology and Metabolism 66, 323-326.

Colonna P, Leloup V \& Buleon A (1992) Limiting factors of starch hydrolysis. European Journal of Clinical Nutrition 46, Suppl., S17-S32.

Crowe TC, Seliman SA \& Copeland L (2000) Inhibition of enzymatic digestion of amylose by free fatty acids in vitro contributes to resistant starch formation. Journal of Nutrition 130, 2006-2008
Daly ME, Vale C, Walker M, Alberti KGMM \& Mathers JC (1997) Dietary carbohydrates and insulin sensitivity: A review of the evidence and clinical implications. American Journal of Clinical Nutrition 66, 1072-1085.

Englyst HN \& Hudson GJ (1996) The classification and measurement of dietary carbohydrates. Food Chemistry 57, 15-21.

Englyst HN, Kingman SM \& Cummings JH (1992) Classifications and measurement of nutritionally important starch fractions. European Journal of Clinical Nutrition 46, Suppl., S33-S50.

Englyst HN, Quigley ME \& Hudson GJ (1994) Determination of dietary fibre as non-starch polysaccharides with gas-liquid chromatographic, high-performance liquid chromatographic or spectrophotometric measurement of constituent sugars. Analyst 119, 1497-1509.

Englyst KN, Englyst HN, Hudson GJ, Cole TJ \& Cummings JH (1999) Rapidly available glucose in foods: an in vitro measurement that reflects the glycaemic response. American Journal of Clinical Nutrition 69, 448-454.

Englyst KN, Hudson GJ \& Englyst HN (2000) Starch analysis in food. In Encyclopaedia of Analytical Chemistry, pp. 4246-4262 [RA Meyers, editor]. Chichester, Sussex: John Wiley \& Sons.

Food and Agriculture Organization/World Health Organization (1998) Expert Consultation: Carbohydrates in Human Nutrition, Food and Agriculture Organization Food and Nutrition Paper no. 66. Geneva: FAO/WHO.

Gannon MC, Nuttall FQ, Westpal SA \& Seaquist ER (1993) The effect of fat and carbohydrate on plasma glucose, insulin C-peptide and triglycerides in normal male subjects. Journal of American College of Nutrition 12, 36-41.

Gallant DJ, Bouchet B, Buleon A \& Perez S (1992) Physical characteristics of starch granules and susceptibility to enzymatic degradation. European Journal of Clinical Nutrition 46, Suppl., S3-S16.

Granfeldt Y, Björck AI, Drews A \& Tovar J (1992) An in vitro procedure based on chewing to predict metabolic response to starch in cereal and legume products. European Journal of Clinical Nutrition 46, 649-660.

Heaton KW, Marcus SN, Emmett PM \& Bolton CH (1988) Particle size of wheat, maize, and oat test meals: effects on plasma glucose and insulin responses and on the rate of starch digestion in vitro. American Journal of Clinical Nutrition 47, 675-682.

Heijene MLA, van Amelsvoort JMM \& Westrate JA (1995) Interaction between physical structure and amylose:amylopectin ratio of foods on postprandial glucose and insulin responses in healthy subjects. European Journal of Clinical Nutrition 49, 446-457.

Holm J, Lundquist I, Björck I, Eilasson AC \& Asp NG (1988) Degree of starch gelatinization, digestion rate of starch in vitro, and metabolic response in rats. American Journal of Clinical Nutrition 47, 1010-1016.

Holt SHA \& Brand-Miller JC (1994) Particle size, satiety and the glycaemic response. European Journal of Clinical Nutrition $\mathbf{4 8 ,}$ 496-502.

Holt SHA, Brand-Miller JC \& Petocz P (1997) An insulin index of foods: the insulin demand generated by $1000 \mathrm{~kJ}$ portions of common foods. American Journal of Clinical Nutrition 66, 1264-1276.

Jenkins DJA, Ghafari H, Wolever TMS, Taylor RH, Jenkins AL, Barker HM, Fielden H \& Bowling AC (1982) Relationship between rate of digestion of foods and post-prandial glycaemia. Diabetologia 22, 450-455.

Jenkins DJA, Wolever TMS, Leeds AR, Gassule MA, Dilawari JB, Goff DV, Metz GL \& Alberti KGMM (1978) Dietary fibres, fibre analogues and glucose tolerance: importance of viscosity. British Medical Journal 1, 1392-1394. 
Jenkins DJA, Wolever TMS \& Taylor RH (1981) Glycaemic index of foods: a physiological basis for carbohydrate exchange. American Journal of Clinical Nutrition 134, 362-366.

Kabadi UM (1991) Dose-kinetics of pancreatic $\alpha$ - and $\beta$-cell responses to a protein meal in normal subjects. Metabolism 40, 236-240.

Lee BM \& Wolever TMS (1998) Effect of glucose, sucrose and fructose on plasma glucose and insulin responses in normal humans: comparison with white bread. European Journal of Clinical Nutrition 52, 924-928.

Normand S, Khalfallah Y, Louche-Pelissier C, Pachiaudi C, Antoine J-M, Blanc S, Desage M, Riou JP \& Laville M (2001) Influence of dietary fat on postprandial glucose metabolism (exogenous and endogenous) using intrinsically ${ }^{13} \mathrm{C}$ enriched durum wheat. British Journal of Nutrition 86, 3-11.

O’Dea K, Snow P \& Nestel P (1981) Rate of starch hydrolysis in vitro as a predictor of metabolic responses to complex carbohydrate in vivo. American Journal of Clinical Nutrition 34, 1991-1993.

Prochaska LJ, Nguyen XT, Donat N \& Piekutowski WV (2000) Effect of food processing on the thermodynamic and nutritive value of foods: literature and database survey. Medical Hypotheses 54, 254-262.

Salmeron J, Manson JE, Stampfer MJ, Colditz GA, Wing AL \& Willett WC (1997) Dietary fiber, glycaemic load and risk of non-insulin-dependent diabetes mellitus in women. Journal of American Medical Association 277, 472-477.

Thomsen C, Rasmussen OW, Christiansen C, Andreasen F, Poulsen PL \& Hermansen K (1994) The glycaemic index of spaghetti and gastric emptying in non-insulin-dependent diabetic patients. European Journal of Clinical Nutrition 48, 776-780.

Trout DL, Behall KM \& Osilesi O (1993) Prediction of glycaemic index for starchy foods. American Journal of Clinical Nutrition 58, 873-878.

van Loon LJC, Saris WHM, Verhagen H \& Wagemakers AJM (2000) Plasma insulin responses of different amino acid or protein mixtures with carbohydrate. American Journal of Clinical Nutrition 72, 96-105.

Welch I McL, Bruce C, Hill SE \& Read NW (1987) Duodenal and ileal lipid suppresses postprandial blood glucose and insulin responses in man: possible implications for the management of diabetes mellitus. Clinical Science 72, 209-216.

Wolever TMS (1991) The glycaemic index: Methodology and clinical implications. American Journal of Clinical Nutrition 54, 846-854.

Wolever TMS (1997) The glycaemic index: flogging a dead horse? Diabetes Care 20, 452-456.

Wolever TMS (2000) Dietary carbohydrates and insulin action in humans. British Journal of Nutrition 83, Suppl., S97-S102. 